\title{
Use of multichannel discrete analyser to reduce unnecessary biochemical tests
}

\author{
A Tarpey, W D Neithercut
}

\begin{abstract}
Aim-To investigate the waste of laboratory reagents which resulted from the process of ordering biochemistry profiles. Method-The frequency of measurement of 15 analytes was recorded during the six months before the introduction of a system of discretionary requesting and analysis of samples (high capacity multichannel discrete analyser), and also during the same six month period one year and two years after its introduction.

Results-The frequency of measurement of 10 of the 15 analytes decreased during the six month period one year after the change to discretionary testing. The remaining five analytes were measured up to $22 \%$ more frequently. There was an overall decrease in the measurement of biochemical tests by 31359 . This created an annual cost saving of $£ 7124$.

In the second year five analytes still continued to be measured less frequently than originally but the remaining 10 analytes were measured more frequently. This resulted in an overall increase in the measurement of biochemical tests by 53678 compared with the six month period before discretionary analysis. The pattern of requests was similar during both periods of discretionary requesting studied and as a result, a small annual cost saving of $£ 1672$ was again made. Conclusion-Discretionary requesting and analysis of tests may eliminate the measurement of clinically unnecessary tests which had previously resulted from the processes of ordering tests. These cost savings may be rapidly eroded by an increase in the laboratory workload.
\end{abstract}

$(\Im$ Clin Pathol 1993;46:459-461)

It has been suggested that up to half of all requests for diagnostic tests in hospitals may be unnecessary. ${ }^{1}$ Many strategies have been examined in order to eliminate unnecessary requests for tests, ${ }^{2-9}$ but different laboratories may undertake different patterns of test analysis in response to the same clinical request. ${ }^{10}$ Wastage of laboratory resources may therefore also occur as a result of the request patterns set by the laboratory.

While clinically unnecessary results may be generated when multichannel continuous flow automated analysers are used to produce multi-analyte profiles, the discrete analysis of samples means that only those tests needed by the clinician are measured. Due to a need to operate several instruments the cost of a discretionary approach to the analysis of samples could exceed that of multi-analyte profile analysis. Multi-analyte profile analysis has therefore become a commonly used method of analysis of large numbers of samples. Clinicians may therefore have become accustomed to using large multi-analyte profile analysis as part of their standard clinical practice. They might be used to screen patients with non-specific symptoms, or for medico-legal reasons. If the use of large multi-analyte profiles has now become a part of standard clinical practice then the introduction of discretionary ordering of tests would not result in a change in the frequency with which routine tests were measured.

An opportunity to study the effect of changing from multianalyte profile analysis to discretionary requesting and analysis arose when it was decided to replace a Chemispek (Rank-Hilger, Margate, Kent) and a Cobas Bio (Roche, Welwyn Garden City, Herts) with an Excel analyser (Monitor Bioscience, Sussex) which has both discrete and multianalyte profile analysis capabilities. The effect of this change on the frequency of measurement of a panel of 15 analytes and the resultant change in reagent cost was studied.

\section{Methods}

The frequency of measurement of each of a 15 test panel of analytes was recorded prospectively by the laboratory computer system between January and June 1990 before a system of discretionary requesting and testing was introduced. The frequency of measurement of the same 15 analytes was also recorded during the months January to June one year and two years after the introduction of a system of discretionary testing and analysis.

The 15 test panel comprised the analytes which had been part of the Chemispek battery of tests produced by the Chemispek (Rank Hilger, Margate, Kent) continuous flow analyser and the "liver enzyme test" battery of enzymes analysed by the Cobas Bio (Roche) (table 1). Following the introduction of the discretionary analyser these 15 analytes were grouped into six discrete profiles each of which could be requested separately (table 1). Chloride, total $\mathrm{CO}_{2}$, and alanine aminotransferase activity (ALT) could also be ordered as individual tests to supplement profiles which did not contain these analytes.

Within the group of six profiles installed on the Excel one was identical with the origi- 
Table 115 test panel of analytes

\begin{tabular}{|c|c|c|c|c|c|c|c|c|}
\hline \multirow[b]{2}{*}{ Tests } & \multicolumn{2}{|c|}{ Profiles before Excel } & \multicolumn{5}{|c|}{ Excel profiles } & \multirow[b]{2}{*}{ P6 } \\
\hline & Chemispek & Liver enzymes & $P 1$ & $P 2$ & P3 & P4 & P5 & \\
\hline $\mathrm{Na}^{+}$ & + & & + & + & & + & + & \\
\hline $\mathrm{K}^{+}$ & + & & + & + & & + & + & \\
\hline $\mathrm{Cl}^{-}$ & + & & & & & & & \\
\hline Total $\mathrm{CO}$ & + & & + & + & & + & & \\
\hline Urea 2 & + & & + & + & & + & + & \\
\hline Creatinine & + & & & + & & + & + & \\
\hline Bilirubin & + & & & & + & + & + & \\
\hline Alkaline phosphatase & + & & & & + & + & + & + \\
\hline AST & & + & & & + & & + & \\
\hline ALT & & + & & & + & & & \\
\hline GGT & & + & & & + & & + & + \\
\hline Albumin & + & & & & + & + & + & + \\
\hline Total protein & + & & & & + & + & + & \\
\hline $\mathrm{Ca}^{2+}$ & + & & & & & + & + & + \\
\hline $\mathrm{PO}_{4}^{3-}$ & + & & & & & + & + & + \\
\hline
\end{tabular}

nal Chemispek profile $\left(P_{4}\right)$, with the exception of the removal of chloride. The new liver function test profile $\left(\mathrm{P}_{3}\right)$ was also a direct successor to the original liver enzyme profile. Clinicians therefore had the opportunity to continue to request the same pattern of tests as before.

Clinicians requested profiles either by completing a request card or through the hospital computer system which electronically transmitted requests for analysis to the laboratory computer.

The effect of the change of profiles on the reagent component of the cost of measurement was calculated using reagent costs for the Excel established during the year 1991/92. The change in cost was measured by comparing the cost of transferring the original workload, without any change to the Excel, with the actual reagent cost of the workload in the two subsequent periods studied.

\section{Results}

The number of samples received by the laboratory increased by an average of $8 \%$ between 1990 and 1991 and by $11.1 \%$ between 1991 and 1992. Despite this general increase in the workload during the first six months of discretionary testing, 10 of the 15 analytes were measured less frequently than during the 6 months preceding its introduction (table 2). The percentage decrease in measurement was greatest for chloride $(-99 \%)$. This test had been removed from all profiles and had to be requested separately. The second largest reduction in frequency of measurement occurred with ALT (-48.9\%). This analyte was available as a component of the "liver function tests" profile or as a separately requestable test. It was not a component of the "screening" profile (P5) used frequently by the hospital doctors as a routine test on admission.

The frequency of measurement of $\mathrm{Ca}^{2+}$, $\mathrm{PO}_{4}{ }^{3-}$, and total $\mathrm{CO}_{2}$ also fell by $27 \%, 28 \%$, and $19 \%$, respectively. Calcium and $\mathrm{PO}_{4}{ }^{3-}$ had been components of the original Chemispek profile but were included in only two of the new profiles (P5 and P6). Total $\mathrm{CO}_{2}$ was also a component of only two profiles, $\left(P_{1}\right.$ and $\left.P_{2}\right)$ but could be requested as a separate test.

The smallest reductions in frequency of analysis occurred with bilirubin $(-13 \%)$, creatinine $(-8.9 \%)$, alkaline phosphatase $(-7 \%)$, albumin $(-4 \%)$ and total protein $(-4 \%)$.

The frequency of analysis of five tests increased during the first six months of discretionary testing. The measurement of $\mathrm{Na}^{+}$, $\mathrm{K}^{+}$, and urea increased by $23.5 \%$. These three tests were the components of the urea and electrolyte profile $\left(P_{1}\right)$. The frequency of measurement of aspartate aminotransferase activity (AST) increased as did that of $\gamma$ glutamyl transferase activity (GGT). Both AST and GGT were included in the screening profile (P5). AST increased by $18.2 \%$ in the frequency of measurement. The greatest percentage increase in frequency of measurement occurred with GGT $(+29 \cdot 7 \%)$. This analyte had originally been available only as a component of the liver enzymes profile but had been included in two of the discretionary profiles-the "liver function test profile" (P3) and the "screening" profile (P5).

The total effect of the changes resulted in a decrease of 31359 tests during the first six months of discretionary analysis. This resulted in a saving of $£ 7124$ in reagent cost during the first 12 months following the introduction of discretionary testing.

During the six month period studied two years after the introduction of discretionary requesting and analysis, five of the 15 tests continued to be measured less frequently than before its introduction (table 2). The frequency of measurement of chloride was reduced by $99 \%$, total $\mathrm{CO}_{2}$ by $13 \cdot 7 \%$, ALT

Table 2 Number of measurements of each test during same six month period before discretionary requesting and one year and two years after its introduction

\begin{tabular}{|c|c|c|c|c|c|}
\hline \multirow[b]{2}{*}{ Analyte } & \multirow{2}{*}{$\begin{array}{l}\text { Before discretionary } \\
\text { requesting } \\
n=\end{array}$} & \multicolumn{2}{|c|}{$\begin{array}{l}\text { One year after } \\
\text { discretionary requesting }\end{array}$} & \multicolumn{2}{|c|}{$\begin{array}{l}\text { Two years after } \\
\text { discretionary requesting }\end{array}$} \\
\hline & & $n=$ & (\% change) & $n=$ & (\% change) \\
\hline $\begin{array}{l}\mathrm{Na}^{+} \\
\mathrm{K}^{+} \\
\mathrm{Cl} \\
\mathrm{Bic} \\
\text { Urea } \\
\text { Creatinine } \\
\text { Bilirubin } \\
\text { AST } \\
\text { ALT } \\
\text { GGT } \\
\text { Alkaline phosphatase } \\
\text { Albumin } \\
\mathrm{Total} \text { protein } \\
\mathrm{Ca}^{2+} \\
\mathrm{PO}_{4}{ }^{3-}\end{array}$ & $\begin{array}{l}43050 \\
42459 \\
27806 \\
42518 \\
43040 \\
35671 \\
31158 \\
23581 \\
18183 \\
18154 \\
28165 \\
28308 \\
27865 \\
28969 \\
27555\end{array}$ & $\begin{array}{l}53173 \\
53155 \\
12 \\
34314 \\
53165 \\
32753 \\
27031 \\
27881 \\
8890 \\
23543 \\
26058 \\
27467 \\
27087 \\
21121 \\
19445\end{array}$ & $\begin{array}{l}(+23 \cdot 5) \\
(+23 \cdot 5) \\
(-99) \\
(-19) \\
(+23 \cdot 5) \\
(-8 \cdot 1) \\
(-13 \cdot 2) \\
(+18 \cdot 2) \\
(-48 \cdot 9) \\
(+29 \cdot 7) \\
(-7 \cdot 4) \\
(-2 \cdot 9) \\
(-2 \cdot 8) \\
(-27) \\
(-29 \cdot 4)\end{array}$ & $\begin{array}{l}62435 \\
62419 \\
18 \\
36690 \\
62418 \\
39545 \\
33716 \\
30746 \\
6623 \\
31075 \\
33949 \\
33348 \\
32974 \\
28036 \\
26168\end{array}$ & $\begin{array}{l}(+45 \cdot 0) \\
(+45 \cdot 0) \\
(-99) \\
(-13 \cdot 7) \\
(+45 \cdot 0) \\
(-10 \cdot 8) \\
(+8 \cdot 2) \\
(+30 \cdot 3) \\
(-63 \cdot 5) \\
(+71 \cdot 1) \\
(+20 \cdot 5) \\
(+17 \cdot 8) \\
(+18 \cdot 3) \\
(-3 \cdot 2) \\
(-5 \cdot 0)\end{array}$ \\
\hline
\end{tabular}


by $63 \cdot 5 \%, \mathrm{Ca}^{2+}$ by $3 \cdot 2 \%$ and $\mathrm{PO}_{4}{ }^{3-}$ by $5 \%$. All the other components of the $15^{4}$ test panel were measured up to $71 \%$ more frequently than in the six months preceding the introduction of discretionary requesting (table 2). This resulted in an increase of 53678 in the number of tests measured. Despite the general rise in the measurement of the 15 tests the pattern of analysis in the second year remained the same as the first year after the introduction of discretionary testing. As a result the cost of the reagent component of the measurement of the 15 analytes during the second year after the introduction of discretionary testing was still $£ 1672$ less than the cost of simply transferring the original workload to the new instrument.

\section{Discussion}

This study has shown that the introduction of a discretionary approach to the requesting of profiles can reduce the measurement of tests which may not actually be required by clinicians for the management of their patients. The clinical users of the laboratory had the opportunity to continue with the original pattern of requesting as replacements for the two original profiles were available. The change in the clinician's pattern of requesting showed that their use of investigations had been directed by the original two profiles. Consequently, unnecessary tests had been conducted.

During the first year after the introduction of the new profiles the frequency of measurement of urea and electrolytes increased by $23.5 \%$. This was greater than the $8 \%$ overall increase in the number of requests for analyses for that year. This disproportionate increase may be explained by a combination of an average increase in the number of requests for this profile plus a transfer of requests from the old Chemispek profile to the urea and electrolyte profile. The remaining components of the Chemispek profile had an average decrease in the frequency of measurement of $13 \%$. These observations indicated that the original frequency of measuring of these tests had been distorted as a result of the composition of the original profiles.

The greatest falls in frequency of measurement occurred with chloride and ALT. Chloride was removed from all profiles and became available only as a separately requestable test. ALT was available as a component of the "liver function test profile" or as a separately requestable test. Although chloride was not included in any of the profiles and ALT in only one, they remained easy to order by adding "+ chloride" or "+ALT" to the request card, or by three additional strokes of a light pen when ordering on the hospital computer system. The reduction in the measurement of these analytes was therefore not achieved through a significant increase in the difficulty with which they could be requested.

The frequency with which ALT measurement was requested decreased again during the second year of discretionary requesting because of a decrease in the number of requests for ALT to be added to profiles which did not contain it. This again showed how infrequently ALT was required for the investigation or management of clinical problems.

If the original workload had been transferred without change to the Excel instrument then over $£ 7000$ worth of reagents would have been wasted by the measurement of unnecessary tests during the first year. A further $£ 1600$ would have been wasted in the second year. If the number of samples received had not increased by $19 \cdot 1 \%$ during the study then the savings made would have been greater.

Consumables and reagents are considered to represent a small part of total laboratory expenditure. ${ }^{112}$ In two studies reductions in numbers of tests by $10 \%$ and $7 \%$, respectively, produced savings of $3.9 \%$ and $1 \%$ of the total annual laboratory expenditure. ${ }^{13} 14$ For this reason it may be considered that savings in this part of the laboratory budget are unlikely to be worthwhile. But as the consumable and reagent cost of analysis of samples is a small component of the total laboratory budget (about 25-30\%), then the amounts of money saved by discretionary testing in this study represented a significant saving in this after of the budget.

Clinicians are often accused of wasting money by requesting unnecessary tests. This study has shown that some of the waste in clinical laboratories also results from the method of requesting tests and from the process of analysis of samples. The sustained reduction in measurement of some tests during the study proved that clinicians know when they receive irrelevant test results. One explanation of the failure of attempts to educate clinicians not to request unnecessary tests may therefore be a recognition that laboratories routinely supply them with unnecessary data.

In conclusion, the production of clinically unnecessary but analytically valid results may occur as a common form of "quality waste" in clinical laboratories. This adds to the cost of the provision of laboratory services.

1 Anonymous. Routine diagnostic testing. [Editorial] Lancet 1989; ii:1190-1

2 Fraser CG, Woodford FP. Strategies to modify the test requesting patterns of clinicians. Ann Clin Biochem 1987; 24:223-31.

3 Martin AR, Wolf MA, Thiboldeau LA, Dzau V, Braunwald E. A trial of two strategies to modify the test ordering behaviou

4 Broughton PMG. The cost of unnecessary tests by day or night. $B r M e d ~ \mathcal{~} 1987 ; 294: 1503-4$.

5 Fawkes FGR. Containing the use of diagnostic tests. $\mathrm{Br}$ Med F 1985;290:488-9.

6 Tiemy WM, Miller ME, McDonald D. The effect on test ordering of informing the physician of the charges for outpatient diagnostic tests. N Engl $f$ Med 1990 322:1499-504.

7 Bareford D, Hayling A. Inappropriate use of laboratory services: long-term combined approach to modify request patterns. Br Med F 1990;301:1305-7.

8 Jenkins D. Investigations: how to get from guidelines to protocols. BrMed $₹$ 1991;302:323-4.

9 McVittie JD, Kay JDS, Keenan J. Reduction of workload by redefinition of test profiles. Ann Clin Biochem by redefinition of test profil

10 Broughton PMG, Worthington DJ. Laboratories respond differently to the same clinical request. Ann Clin differently to the same
Biochem 1989;26:119-21.

11 Broughton PMG, Woodford FP. Benefits of costing in the clinical laboratory. $\mathcal{f}$ Clin Pathol 1983;26:1028-35.

12 Stilwell JA. The costs of a clinical chemistry laboratory. $\mathcal{F}$ Clin Pathol 1981;34:589-94.

13 Winkelman JW. Less utilisation of the clinical laboratory produced disproportionately small true cost reductions. Hum Pathol 1985;34:499-501.

14 Gamma R, Nightingale P, Broughton PMG, Peters M. Routine diagnostic testing. Lancet 1989;ii:1528-9. 